\title{
A Study of Knitted Fabric from Thai Silk Waste Yarin
}

\section{Peeraya Sramala}

Faculty of Decorative Arts, Silpakorn University. 31 Na Phra Lan Road, Phra Borom Maha Ratchawang Sub-district, Phra Nakorn District, Bangkok 10200. psramala@hot-mail.com

\begin{abstract}
Thai silk is a part of Thailand regional cultural heritage. The unique characteristics are gummy, sticky substance and shining. Thai silk Industry share a common problem to other industries, the process produces a lot of waste. A solid waste from Thai silk can be classified into three types: Incomplete cocoons broken silk yarn; and silk fabric waste. Generally, these waste use for reuse in the business roles such as fashion accessories and decorative product. In order to adding value to Thai Silk waste can be done by knitted fabric properties: more flexible and able to produce in flat, seamless, and three dimension. The recycle concept led to following studies: 1) To do an experiment of yarn spinning from Thai silk waste fibre; 2) To experiment a knitted fabric from a yarn of Thai silk waste and; 3) To experiment yarn dyed and knitted fabric piece dyed by natural dyeing colour. A method of study consist of fibre preparing and spinning by hand, the equipment to develop knitted fabric are hand knitting and knitting machine, the natural dyeing colour come from coffee grounds, Turmeric, Red cabbage, and Mulberry. The result of study are: 1) Fibre and spinning experiment shown a yarn is uneven; yarn from broken silk yarn, silk fabric waste, and incomplete cocoon fibre are sticky and softly touch respectively; 2) Knitted fabric experiment showed that the production by hand knitting are soft and flexible than a knitting machine. While knitting machine fabric is smooth surface than hand knitting fabric and; 3) Natural colour dyeing experiment showed that the colour absorption of yarn dyed is better than piece dyed. In conclusion, a result of the study can be used as a guideline idea to create new knitted fabric made from Thai silk waste to present the aesthetic values through textures, colours, structure and pattern.
\end{abstract}

Keywords: knitted fabric, thai silk waste

\section{INTRODUCTION}

\section{Thai Silk}

Thai silk is a part of the national cultural heritage. Thai Sericulture was founded long time ago, Sericulture is an art of rearing silkworm for the producing cocoons as the raw material for silk production. The evidence record shows that in 1903 AD. (2446 BE.) His Majesty King Chulalongkorn be kind to founded the "Silk Artisan Department" in Bangkok to promote Thai sericulture. Thenceforward, a development of Thai Sericulture is grown up steadily. At the present, Her Majesty Queen Sirikit be kind to establish "Foundation for the Promotion of Supplementary Occupations and Related Techniques of Her Majesty Queen 
Sirikit" to sustain this objective. By the Queen's speech "Silk sericulture is a part of increasing farmer income. In addition, it is a cultural heritage and aesthetic of Thailand that has transferred from generation to generation for a long time. Therefore, if Thai economy is changing, Thai silk sericulture should be continuing development." The present is the Queen Sirikit Department of Sericulture response the Queen's speech by collect Local Thai silkworm breed to research and breeding in order to get the strong varieties and high yielding. At the present time, 24 breed of pure Thai silkworm and crossbreed in the collection. (The National Institute of Sericulture Queen Sirikit, 2008, pp. 45-53).

Detail of the silkworm rearing process is consisted of two steps: rearing the newly born silkworm and wait until the worm developed into cocoon. Thai cocoon has a special property, it is a small and slim shape, but it's durable in the environment as well. Filament silk yarn is very fine and has special physical characteristics never seen in another silk, it's cross-section is triangular shape making beautiful light refraction. Thai silk yarn is hand reeled and when dropped in wicker basket it's become the fine silk yarn. In this process the spinster found that the yarn is more soft touch, flexible and shiny than machine reeling method. Moreover, when Thai silk clothed is worn and moved, it produces a special noise called silk sound. The most strength of Thai silk never found in the yellow silk type which consisted of 18 kinds of amino acid. The percentage of the amino acid is over 34.5 that higher than those of other country. (The National Institute of Sericulture Queen Sirikit, 2008, pp. 34-39). All of this is a result of the unique characteristics of Thai silk, it is quite a gummy, sticky substance and shine. Nowadays, Thai silk produces both remain in the household and become to the factory, most are in the northeast area. Also, Thai government has promoted the development of cocoon gene, manufacture technology and product design in all of this to make the best quality. People are encourages to use of Thai silk.

\section{Thai Silk Waste}

Thai silk industry like the other industries, it produces a lot of waste. A solid waste from Thai silk can be classified into three types: incomplete cocoons, broken silk yarn, and silk fabric waste. Among the three types, the first one is incomplete cocoons: imperfect cocoons which cannot be reeled commercially such as double cocoons, feeble cocoons, pierced cocoons, piques, and rates. The second type is broken silk yarn: a waste products in reeling, winding, throwing, and weaving. The last category is silk fabric waste: a waste products in apparel industries, and decorative product industries. (F. R. McGowan, Charles W. Schoffstall, \& A. A. Mercier, 1924, pp. 582-583; K. Murugesh Babu, 2013, p. 48; Thai Textile Institute, n.d., p. 52) However, the statistic of this waste cannot be estimated because the factories have been different management. (Thai Textile Institute, n.d., p. 63) Generally, these waste use for reuse in the business roles such as fashion accessories and decorative product. Academically, Thai researchers conducted a study of waste in several fields to achieve high benefit. The detail are as follows:

- Nonwoven Fabric Production Using Waste Silk. 
The aim of the project is to study the possibility of producing a nonwoven fabric from waste silk by conventional carding followed by the thermal bonding process. It also covers the study of physical and mechanical properties of the products to verify whether they are acceptable for textile applications. The results show that the nonwoven is yellowish white, lustrous and acceptable strength and softness. (Kachamas Tumrongsak, 1994, p.จ; 5th Thai alphabet).

- The Development of new Mixed Fibre from Waste Cocoon and Other Plant Fibres.

The research was to develop new mixed fibre from a waste cocoon and other plant fibers. The researcher found that waste cocoon has special properties to produce new mixed fibre when mixed with five kinds of plant fibres, namely cotton yarn, linen yarn, pineapple yarn, ramie yarn, and hemp yarn. The research results indicated that fiber from waste cocoon mixed with hemp yarn is good for producing home textile as it has the maximum breaking strength while fiber from waste cocoon mixed with pineapple yarn is appropriate for producing clothes. (Kittisak Ariyakuare, 2010, p. 369).

- Yarn Spinning from Silk Wastes in Weaving Process.

The research aimed to recycle silk wastes from the weaving process by transforming into spun yarns using ring spinning system. In this study silk wastes from both handloom and rapier loom were used and cut at a length of $38 \mathrm{~mm}$. suitable for the cotton spinning process. The treated fibres fed into the opener, carding machine, draw frame, roving machine and ring spinning machines. The physical from this properties were then used characterize the properties of resulted yarns. The yarns were knitted to make gloves, socks and knit fabrics. It was established that silk wastes from both handloom and rapier loom were able to make yarns. The yarn count of the recycled yarn from the waste of handloom was $18.37 \mathrm{Ne}$ with the average twist of 17.22 turns per inch. The tenacity of yarn from the waste of handloom was $14.40 \mathrm{cN} /$ tex. The yarn count of the recycled yarn using waste from the rapier loom was $16.51 \mathrm{Ne}$ with the average twist of 16.53 turns per inch. The tenacity of yarn from waste of rapier loom was $20.27 \mathrm{cN} /$ tex. The recycled yarns could be knitted into end-use product such as gloves, socks and knit fabrics. (Pisut Chankum, 2011, p. ง; 4th Thai alphabet).

- The Development of a Carding Machine and a Twisting Silk Machine for Eri Silk.

The purpose of this research was to develop a carding machine and twisting machine for produce eri fiber and yarn. A carding machine decomposes degumming cocoons and forms it into cohesiveness silk filament. Silk filament was then spun and twisted in the twisting machine. Factors to test machine functionality were teeth of carding head which were aligned in straight and zigzag pattern. Speeds of fiber feeding were $0.24,0.32$, and 0.4 meter per minute. From the experiments of the carding machine, it can be found that almost cocoons were decomposed when using zigzag pattern. The speed of cocoon feeder was about 0.24 meter per minute. From twisting machine testing, results pointed out a different speed of fiber feeding provided different size of yarn. The properties of eri silk obtained from the machine were similar with eri silk produced from the traditional method. Therefore, carding machine and twisting machine developed in this research can help 
farmers to increase production and support the eri silk industry development. (Siriluk Wongkasema and Puripong Aksornpim, 2015, pp. 801-806)

According to The research, Thai researcher was studying fibre processing, equipment, and a method to transfer into yarn and nonwoven suggesting that Thai silk waste can be applied in multiple propose and expect that can be developed more and more.

\section{Spinning Thai Silk Waste}

It may be broadly divided into five main divisions to make cocoons be a yarn: degumming, dressing or combing, preparatory operations, spinning, and finishing. A detail of practice is begun from degumming: removing the gum or sericin from cocoons. After that dressing or combing: a process to separates out short fibre, straighlinear and lie parallel to each other. The next step is preparatory operations: a process that disentangles, cleans and intermixes fibers to produce a continuous web; sliver and roving that suitable for spinning.

The following step is spinning: a process to grouping a fibre twist together to form a long continuous length of interlock called yarn. Finally, after spinning is finishing: a process to arrange yarn number, cleaning, reeling, and bundles. (K. Murugesh Babu, 2013, pp. 48-52).

Another method to make a fibre from the cocoon is Mawata, each cocoon is opened up, turned inside out and stretched on a frame. Layer upon layer of fine silk is stretched in this manner and then hung out to dry like a handkerchief. When dry, the Mawata is fixed to nails projecting from a rotating stand, fluffed up and spun, making a soft weft thread to be used with the reeled warp. (Ann Hecht, 2001, pp. 129)

In the case of broken silk yarn and silk fabric waste, the cotton spinning process is applied to produce a yarn. The process is about combing and carding broken yarn by machine. Silk fabric waste should be separated warp yarn and weft yarn, then comb and card by hand, after that, hand spin or machine was practice. (Thai Textile Institute, n.d., p. 59).

\section{Knitted in Art and Design}

Knitted fabric formed by intermeshing loops of a single yarn or set of yarns together, there are three type of knitting tool: are used Hand knit, domestic machine, and Automatic machine. The properties of knitted fabric are high flexible as a result to comfortable wearing. The fabric is soft, whether thick and thin, wrinkled resistantly and easily recover form it's wrinkly. Knitted fabric can be produced by body sizing, it is suitable and convenient fitting wear. (Pornchai Tulpijit, 2009, pp. 2-5)

In recent years knitting has seen a resurgence in popularity, with many different approaches emerging - from creative international runway fashions through to the application of knitting in interiors in the form of lightshades, cushions, floor coverings, chairs, and blinds, all based on the versatility of stitch structure. Furthermore, conceptual artists who exploited the traditional craft of knitting can create installations of all 
dimensions, from large scale public sculptures to miniatures and wearable art, all of which challenge our preconceptions of knitting. (Carol Brown, 2013, p. 6)

The famous artist and designer are as following sentence:

\section{Fashion}

Mark Fast: Mark's unmistakable womenswear pieces, created on a domestic knitting machine, have challenged perceptions of knitted garments. He is famous for devising his own innovative stitches, and embracing stretch yarns to create contemporary sculptured garments. The pieces have a unique design signature and a large following. (Samantha Eliott, 2015, p. 26)

Ramón Gurillo is a fashion designer from Valencia, Spain, his influences are multicultural: traditional Valencian craftsmanship combined with a London sensibility and a 'hint of rock 'n' roll'. The Spanish designer intricate designs, with recurring open-weave stitches, often cocoon- like in silhouette, use the finest yarns, refined cottons, linens and crêpes. (Samantha Eliott, 2015, p. 34)

\section{Art}

B-Arbeiten, the German guerrilla knitting group known as B-Arbeiten - an adaptation of the German word meaning 'to edit' or 'to alter' - are known for using yarn bombing to decorate public objects such as trees and ferries and, more recently, to create tipi structures. (Samantha Eliott, 2015, p. 116)

Magda Sayeg, Credited as the mother of yarn bombing (which can loosely be defined as impermanent graffiti artworks), her work has influenced and inspired a generation of graffiti knitters to go out and create. The art work has evolved into a solo pursuit - innovative in her approach, projects include working with corporate companies (Absolut Vodka, Madewell, Mini Cooper), art exhibitions, large installations and community projects. Identifying as an artist, a collaborative worker, a teacher and an activist, she constantly challenges herself and the environment around her. (Samantha Eliott, 2015, p. 172)

\section{Design}

A highly regarded textile artist in Japan in the 1970s, Toshiko Horiuchi MacAdam realized that she wanted to make works designed for children's play rather than for exhibition in galleries and museums. Her first high profile playspace was created in 1979 and housed at Okinawa Memorial National Park, followed by knitted wonder space at the Hakone OpenAir Museum. With her husband Charles MacAdam, Toshiko established Interplay Design and Manufacturing in 1990, creating and promoting art and play for children in national parks. Japanese Artist is currently working on pieces to be installed in her North America based. (Samantha Eliott, 2015, p. 198) 
Annette Bugansky, combines a background in fashion and costume design with a nostalgic love of knitted fabric and skilled slip casting techniques to transform soft, tactile surfaces into usable vases, lamps, cups and sculptural pieces. (Samantha Eliott, 2015, p. 190)

\section{Natural dyeing}

Natural dyes are colorants derived from plants or minerals, the major of natural dyes are a difference part of vegetable from plant sources such as roots of vegetation, many part of berries, bark, leave, and wood. Natural dyestuffs are often abundant and freely available in gardens or hedgerows. Linda Rudkin (2007, p. xi) said "Working with natural dyes, like the rest of the creative process, is an adventure. As long as basic principles and process are observed, there will be few disappointments and many delightful surprises". The following sentence to support her statement are first, the results are not entirely predictable. Many variables that can affect the outcome such as the age of the plant material, the season, the amount of recent rainfall, the Ph. of the soil, the hardness of the water and, most significantly, the ratio of dyestuff to fibreany of these factors can make a noticeable difference. Second, most natural dyes will hold their colour as well if a few basic principles are understood and processes observed. Also, given the same care and consideration as any others such as be kept out of direct sunlight, it should be main vibrant for just as long. Third, natural dyeing is not at all difficult and it is a great deal more interesting. There is something very satisfying about growing to find the means to produce natural colours for a piece of textile work, especially these soft, harmonious colours that would be difficult or impossible to achieve using commercial dyes. (Linda Rudkin, 2007, pp. ix-x)

The basic dyeing process are begin from preparing equipment consist of large pan, steel rod or knitting needle, other tool can be are such as tongs, rubber gloves, dust mark, waterproof apron, weighing scales, thermometer, sieve, jelly bags, muslin or coffee filters, scales, plastic sheeting, heat source, large bowl, and glass jar. The recipe for a specific material and all techniques and project are base on $100 \mathrm{~g}(31 / 2 \mathrm{oz})$ and $31 / 2-41 / 2$ litres (6-8 pints) water. The dyeing step is preparing the material begun by cleaning, follow by putting a dyestuff in water and thirty to sixty minute boil. The next step is strain and transfer only liquid to pot, damp yarn and a piece of knit fabric and simmer for about an hour. Rinse with water until a water clear and hang to dry with air drying. (Jackie Crook, 2007, pp. 7-8, 23-28)

All of above, it's inspire to study to develop knitted fabric from Thai silk waste to create an art form. The aim of this research are, first is to do an experiment of yarn spinning from Thai silk waste fibre. Second is to experiment a knitted fabric from a yarn of Thai silk waste. And third is to experiment yarn dyed and knitted fabric piece dyed by natural dyeing colour. Finally, the result will be applied to create Art form. 


\section{METHOD AND EXPERIMENT}

\section{Material and Equipment}

Material

A method of study consists of Thai Silk waste: degummed incomplete cocoons; broken silk yarn; and silk fabric waste. The natural dyeing colour is coffee grounds, Turmeric, Red cabbage, and Mulberry, water and salt.

\section{Equipment}

Mesdanlab: Lab carding machine serial 137 and Lab drawing machine serial 21. Thai tradition hand spinner, knitting needle no. 12, knitting machine: Brother HK-836 (gauge $5.5)$

\section{Fiber Preparation}

Preparation of Thai silk waste to make the suitable fibre for spinning are two methods as the details below: the first method is machine preparation. Mesdanlab: Lab carding machine serial 137. Firstly, set a group of three raw materials, then cut degummed cocoons into $3 \mathrm{~mm}$, broken silk yarn, and silk fabric waste (it should be only a silk thread that separate from fabric) into $3 \mathrm{~cm}$. Secondly, weigh each fibre 15 gramme and feed into a carding machine for three times. In this step the fibre will be separate and straighten, the result is a pad of fibre. Thirdly, after carding is drawn a fibre and feed each fibre pad into Mesdanlab, is used Lab drawing machine.

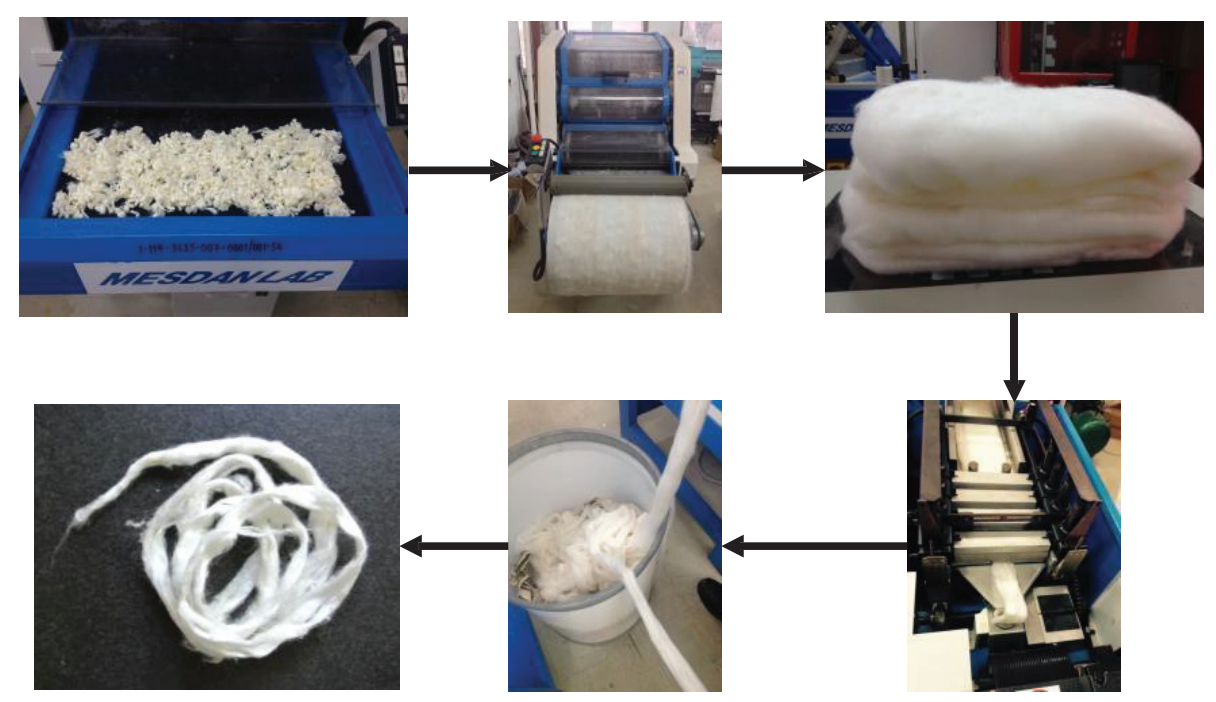

Figure 1. A process of Carding and drawing a cocoon into a fibre serial 21. The result is a long bundle fibre called sliver as presented in figure 1.

The second method is hand preparation. This method applied for cocoons only, begin from soaking a degummed cocoons in warm water, then gently stretched into a gossamer film onto a square frame, do overlay about ten sheets After that, remove a silk hanky from a square frame and place it hang to dry, the dried silk square sheet known as mawata or silk hankies. The last step, poking a hole in the centre of a mawata sheet. Put the hands through 
the hole and stretching the fibre into a large band. Keep extending the circle carefully and pulling the circle thinner by hand until the size is reduces fibre to the diameter about one centimetre, the outcome is a long band fibre called roving as presented in figure 2 .

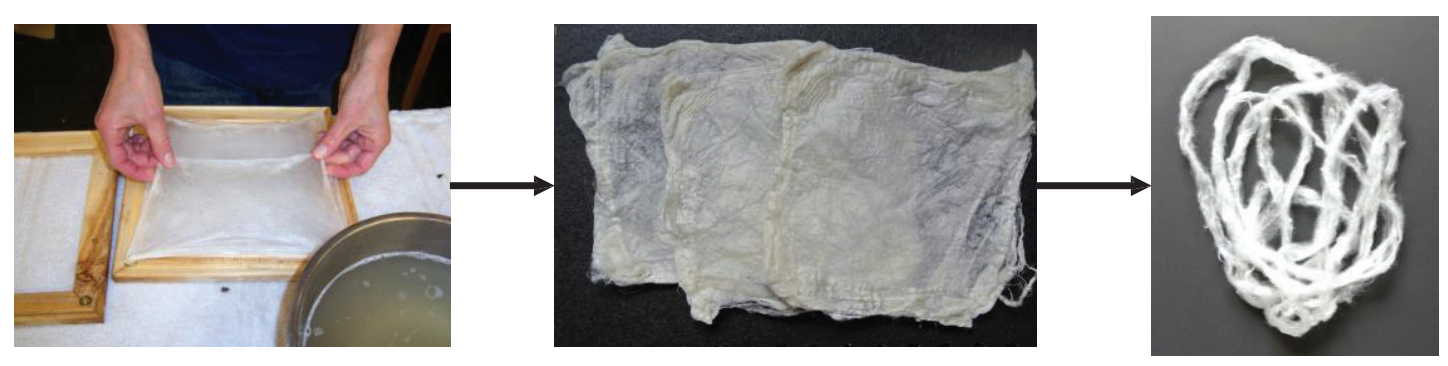

Figure 2. Cocoons made into Mawata and roving

\section{Spinning process}

The objective of this process is grouping fibre a twist together to form a continuous stand by traditional Thai hand spinner and become to made single yarn. Both sliver and mawata or silk hankies will be led to direct spinning. This process was done by local spinster in Bann Nong Bau Dang, Chaiyapum Province, Thailand. The number of yarn is not be specify, it was controlled depending on raw material, spinning tool and spinster as presented in figure 3 and 4.
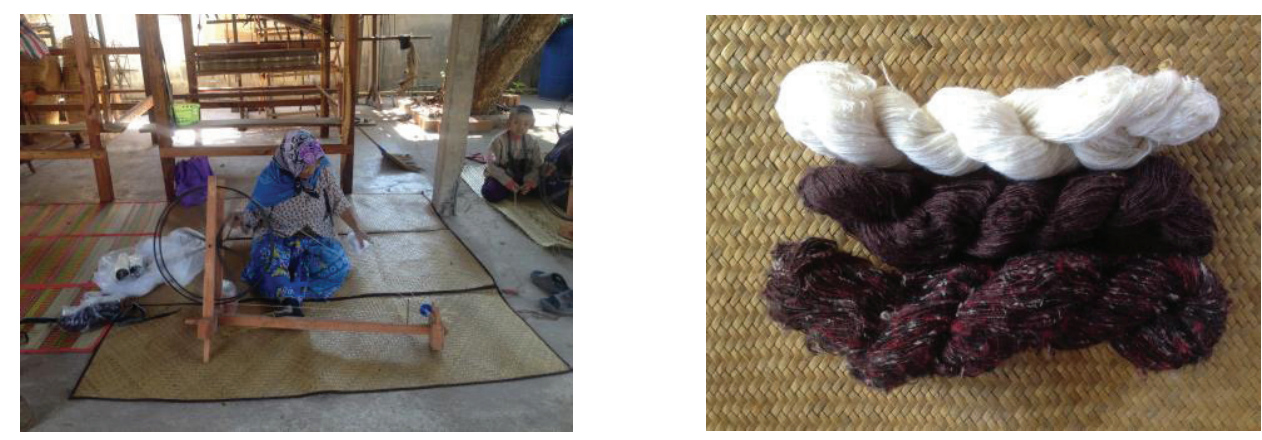

Figure 3. A process of Hand spinning and yarn from cocoon, Silk fabric waste

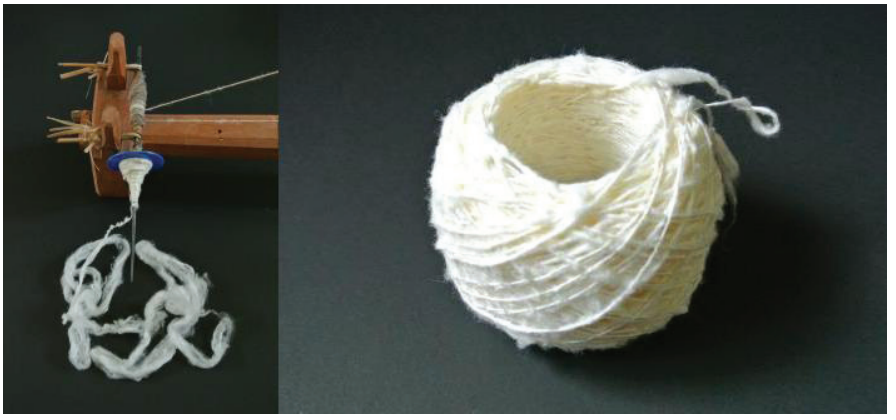

Figure 4. A yarn from Thai cocoon mawata 

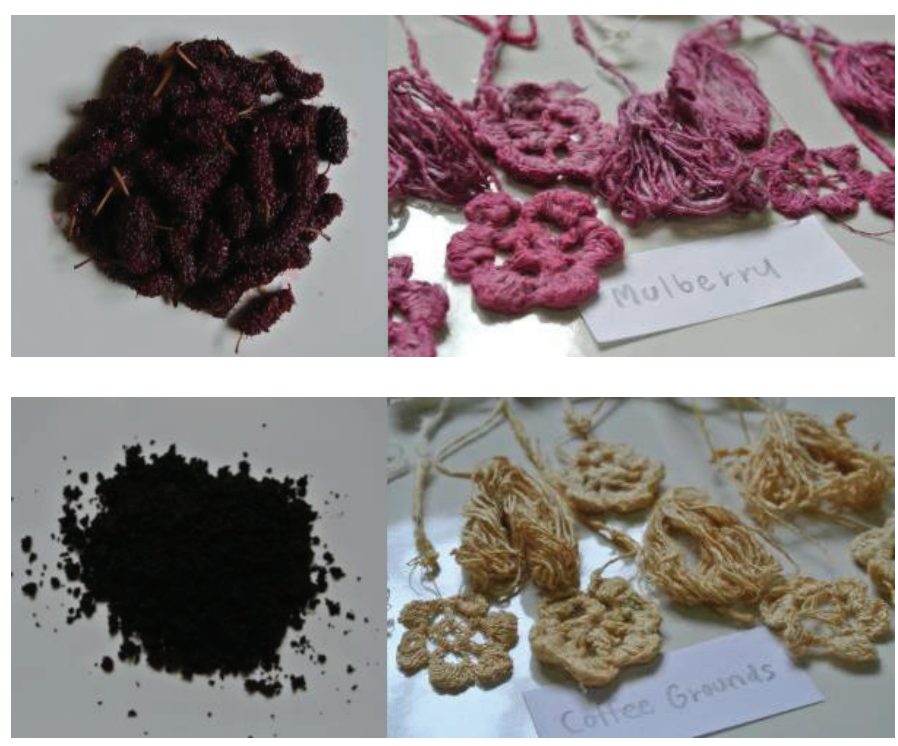

Figure 5. Mulberry and a sample of yarn and piece dyed

Figure 6. Coffee grounds and a sample of yarn and piece dyed

\section{Dyeing Process}

Dyeing method of this study is applied to yarn dyed and piece dyed by natural base colour. There are mulberry, coffee grounds, red cabbage, and turmeric. The material for dye are yarn and fabric from cut cocoons and mawata by the process as bellow.

\section{Mulberry}

The process of mulberry and coffee ground dyeing is similar. First step is mix one cup of mulberry, one teaspoon of salt or one cup of coffee grounds in four cups of water. After that bring to boil, turn off the stove and leave to cool, strain and transfer only liquid to pot, add damp yarn and a piece of knit fabric and simmer for about an hour, stir every fifty minutes to make sure the that fabric is picking up the dye evenly. Finally, rinse with water until clear solution is obtain and hang to dry with air drying. The outcome as presented in figure 5 and 6.

\section{Red cabbage}

Red cabbage and turmeric dyeing is same procedure, to begin with put one cup of chopped cabbage or one cup of chopped fresh turmeric in four cups of water and bring to boil about a thirty minute. Next step is strain and transfer only liquid to pot and continue boil on medium heat, add damp yarn and a piece of knit fabric and simmer for about an hour, stir every fifty minutes to make sure that the fabric is picking up the dye evenly. The last step, rinse with water until clear solution is obtain and hang to dry with air drying. The outcome as presented in figure 7 and 8.

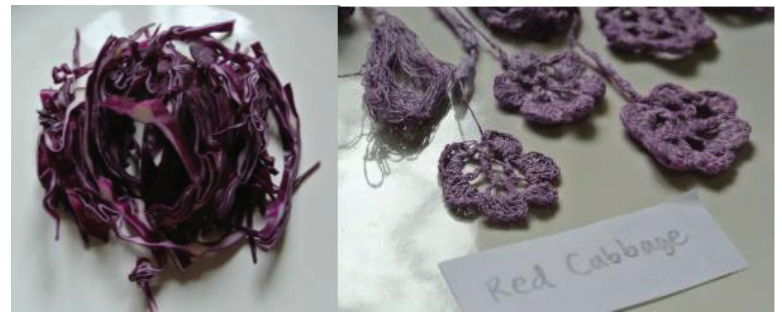

Figure 7. Red cabbage and a sample of yarn and piece dyed 


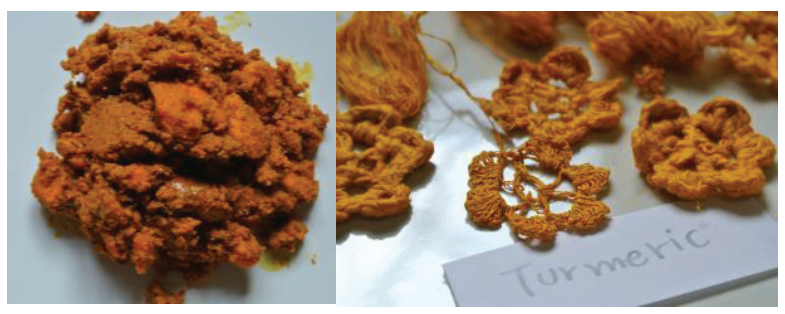

Figure 8. Fresh turmeric and a sample of yarn and piece dyed

\section{Knitting Process}

This study is require two methods: knitting needle no.12 and Brother knitting machine model Brother HK-836, gauge 5.5. These tools use for knit a yarn from three raw material: 1) degummed incomplete cocoons (cut cocoons and mawata); 2) broken silk yarn; and 3) silk fabric waste.

The knitting needle no.12 is first practice, each yarn will be knit into ten square centimetres of fabric. The next practice is machine knitting, each yarn will be knitted two piece of ten square centimetres of fabric, one of this will be bring to wash and dry. In addition, yarn from cut cocoons and mawata will be knit four piece of small circle diameter about three centimetres by crochet, and the next step is dying. The outcome as presented in figure 9 and 10 .

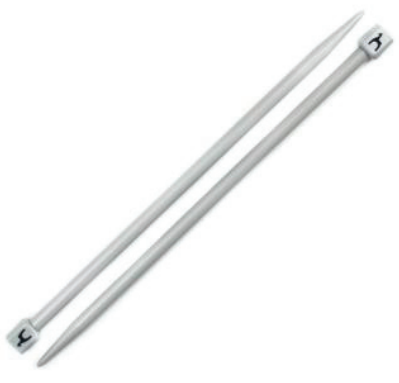

Hand knitting needle no. 12

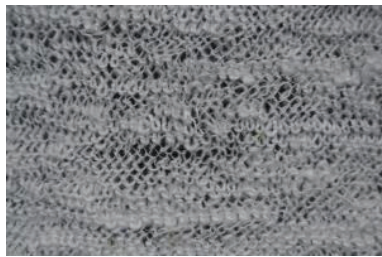

cut cocoons

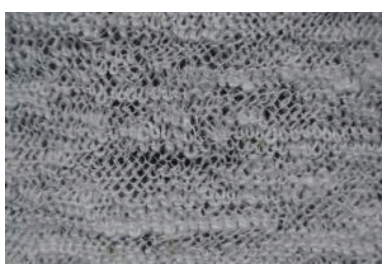

broken silk yarn

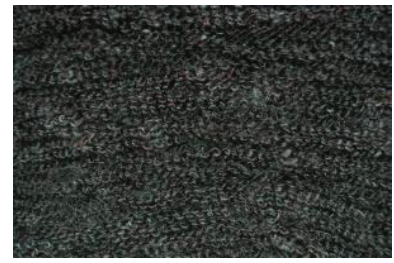

silk fabric waste

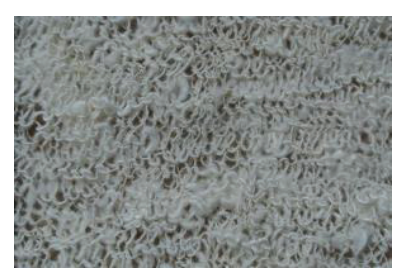

mawata

Figure 9. Hand knitting needle and a sample of knitted

\section{RESULTS AND DISCUSSION}

\section{Fibre preparation}

The result of fibre preparation are three sliver and one roving as following: 
The result of experiment shown all of raw material can be card and draw by machine. Fibre of silk fabric waste is easy to separate and straighten than broken silk yarn and degummed incomplete cocoons. As a result, the fibre from silk fabric waste is very fine, next is broken silk yarn, and the last is degummed in complete cocoons. Moreover, it can be setting into sliver better than another two material, sliver size of three raw material was about three to five centimetres. In the case of mawata or hankies, Thai cocoon can be expanded into a sheet about ten square centimetres. While transfer a sheet of mawata to be a roving by hand, it was sticky but not difficult to pull and control a roving size.

\section{Yarn spin}

The result of yarn spin experiment by local tool and spinster in Thailand is four type of yarn. There are cut cocoons yarn, yarn from mawata, broken silk waste yarn, and silk fabric waste yarn. Since sliver from silk fabric waste is smooth as a result to spin easily, next is sliver from silk broken yarn. Meanwhile a sliver from degummed cocoons is sticky consequently it was hard to feed in to a spinner. However, the result of practice shown a yarn is uneven; yarn from broken silk yarn, silk fabric waste, and incomplete cocoon fibre are sticky and softly touch respectively. In the case of mawata, by the property of mawata roving: even and long band. The material is easily and rapidly spinners. The result is uneven, sticky and middle softly touch.

\section{Dyed}

The result of natural colour dyed experiment obtained that colour from: mulberry is pink, coffee ground, light brown, red cabbage is purple and turmeric is redish yellow. In the case of colour absorption, yarn dyed absorb better than piece dye.

\section{Knitted fabric}

Knitted fabric experiment shown that the production by hand knitting are softer and more flexible than machine knitted produce. The surface quality of the machine knitted fabric is smoothes than hand knitted fabric. In addition, washed knitting machine fabric is transferred to hard skin touch and reduced flexibility. See the explanation bellow:

\section{- Hand knit}

The fabric surface is rough, medium flexible, but soft touch. A fabric from broken silk yarn is the most softly touch feeling. The next example is fabric from silk waste fabric, silk hankies, and cut cocoons respectively.

\section{- Machine knit}

The fabric surface is rough but smoother than hand knitted fabric. Fabric flexible is less than fabric knit by hand knitted type fabric. There are soft touch by hand like a fabric knit by hand, the most softly is fabric from broken silk yarn is the most softly, next is fabric from silk waste fabric, silk hankies, and cut cocoons respectively. 


\section{CONCLUSION}

In conclusion, a result of study can be used as a guideline to make a new knitted fabric from Thai silk waste to present the aesthetic and art form and aesthetic values through textures, colours, structure and pattern. The further study will be mention as the following:

1. The consideration of raw material and equipment that suitable to making a yarn by relate to process. Firstly, there should be short procedure and uncomplicated, quickly, low cost, low energy. Secondly, it could be easy and rapidly to develop, created and design a new yarn in various form. and

2. The consideration of yarn properties that suitable to create knit art form relate to technic, pattern, shape, and form.

\section{REFERENCES}

Ann Hecht. 2001. The Art of The Loom: weaving, spinning and dyeing across the word. Hong Kong: The British Museum.

Carol Brown. 2013. Knitwear Design. China: Laurence King.

F. R. McGowan, Charles W. Schoffstall, and A. A. Mercier. 1924. "A Study of Silk Waste used for Cartridge-bag cloth, with in Appendix on The general Classification of Waste Silk". TECHNOLOGIC PAPERS OF THE BUREAU OF STANDARDS, 18, 582-583.

Jackie Crook. 2007. Natural Dyeing. China: Gaia Books.

Kachamas Tumrongsak. 1994. Nonwoven Fabric Production Using Waste Silk. Master's thesis. Applied Polymer Science and Textile Technology, Chulalongkorn University.

Kittisak Ariyakuare. 2010. The Develoment of New Mixed Fiber from Waste Cocoon and Other Plant Fibers. The 2nd RMUTP International Conference.

K. Murugesh Babu. 2013. Silk Processing, properties and applications. India. Lightning Source.

Linda Rudkin. 200). Natural Dyes. China: A\&C Black.

Pisut Chankum. 2011. Yarn Spinning from Silk Wastes in Weaving Process. Master's thesis. Engineering in Textile, Faculty of Engineering, Rajamangala University of Technology Thanyaburi.

Samantha Eliott. 2015. Knit: Innovations in Fashion, Art, Design. China: Laurence King. Pornchai Tulpijit. 2009. Structure Properties and Utilizer of Knitted Fabric. [copyprint] Bangkok: Rajamangala University of Technology Krungthep.

Siriluk Wongkasema and Puripong Aksornpim. 2014. The Development of a Carding Machine and a Twisting Silk Machine for Eri Silk (Procedia Engineering 1002015). Retrieved from www.sciencedirec.com.

The National Institute of Sericulture Queen Sirikit. 2008. The miracle quality local Thai silk. Bangkok: Amarin Printing and Publishing.

Thai Textile Institute. (n.d.). The productivity of natural fibre development as a raw material by using industrial format

(โครงการเพิ่มประสิทธิภาพการใช้วัตถุดิบภาคเกษตรด้วยการพัฒนาเส้นใยธรรมชาติเชิงอยตสากรรม)., n.p. 